\title{
Ischemic Colitis Caused by Bowel Preparation for Colonoscopy
}

\author{
Takuji Kawamura ${ }^{\text {a, c } \mathbb{D} \text {, Naokuni Sakiyama }}{ }^{\text {a }}$, Kiyohito Tanaka ${ }^{\mathrm{a}}$, \\ Isao Yokota ${ }^{\mathrm{b}}$, Koji Uno ${ }^{\mathrm{a}}$, Kenjiro Yasuda ${ }^{\mathrm{a}}$
}

\begin{abstract}
Background: Ischemic colitis is an adverse event which may occur during bowel preparation for colonoscopy. This study aims to clarify both the incidence and the risk factors of this complication.

Methods: This was a single-center, retrospective, observational study. All outpatients who were prescribed standardized preparation drugs for colonoscopy at the Kyoto Second Red Cross Hospital between November 2011 and March 2020 were included in the study. A split bowel preparation was carried out as follows; magnesium citrate with or without sodium picosulfate hydrate was/were used as a preparation drug on the day before the colonoscopy, and polyethylene glycol electrolyte solution or sodium phosphate was used on the morning of the endoscopic procedure. Patients were extracted from the electronic medical records and matched with the endoscopy database by examination date and hospital identification number. Following the endoscopic findings, both the incidence and risk factors for ischemic colitis arising after bowel preparation were examined.
\end{abstract}

Results: Among the 14,924 patients analyzed, ischemic colitis was observed in 14 patients $(0.09 \%)$. Multivariate analysis revealed that old age ( $\geq 75$ years old) and strong preparation (magnesium citrate with sodium picosulfate and polyethylene glycol electrolyte solution) for constipated patients were independent risk factors for ischemic colitis (odds ratio: 3.64 (95\% confidence interval (CI): 1.36 - 9.77) and 4.27 (95\% CI: 1.45 - 12.53), respectively).

Conclusions: The age 75 years and above and strong preparation for patients with constipation were independent risk factors for ischemic colitis prior to colonoscopy. Careful attention should be paid to bowel preparation before colonoscopy for patients aged $\geq 75$ years and for those with constipation.

Keywords: Colonoscopy; Colitis; Ischemia; Laxatives

Manuscript submitted August 28, 2021, accepted September 23, 2021

Published online October 14, 2021

aDepartment of Gastroenterology, Kyoto Second Red Cross Hospital, Kyoto, Japan

bepartment of Biostatistics, Hokkaido University, Sapporo, Japan

${ }^{\mathrm{c} C o r r e s p o n d i n g ~ A u t h o r: ~ T a k u j i ~ K a w a m u r a, ~ D e p a r t m e n t ~ o f ~ G a s t r o e n t e r o l o g y, ~}$ Kyoto Second Red Cross Hospital, 355-5 Haruobi-cho, Kamigyo-ku, Kyoto 602-8026, Japan. Email: kawamurat@kyoto2.jrc.or.jp

doi: https://doi.org/10.14740/gr1461

\section{Introduction}

Colorectal cancer is the second leading cause of cancer-related deaths in Japan [1]. It has been reported that colonoscopic intervention, including polypectomy of adenomatous lesions, can prevent death from colorectal cancer [2-6]. However, several lesions are missed during colonoscopy, and the adenoma detection rate (ADR) is a good quality indicator of colonoscopy $[7,8]$. Patients who undergo colonoscopy by an endoscopist with a high ADR have a lower risk of subsequent colorectal cancer $[7,8]$.

Adequate bowel preparation is essential in reducing missed lesions $[9,10]$. Low-quality preparation results in a 5\% reduction in ADR compared to high- or intermediate-quality preparation [11].

Ideally, bowel preparation should be safe, convenient, tolerable, and inexpensive [9]. Polyethylene glycol electrolyte solution (PEG-ELS) is widely used as a bowel preparation agent. In the USA, 4 L of PEG-ELS is generally administered [12], but a laxative can be used before administering PEG-ELS to reduce the total volume of lavage solution [9]. Sharma et al reported that administration of magnesium citrate before lowvolume (2 L) PEG-ELS improved patient tolerance and demonstrated non-inferior efficacy of bowel cleansing compared to 4 L of PEG-ELS [13]. For over 20 years, our institution has adopted a preparation regimen comprising magnesium citrate with or without sodium picosulfate administered the day before the colonoscopy and $2 \mathrm{~L}$ of PEG-ELS administered on the morning of the colonoscopy.

Unfortunately, several adverse events of bowel preparation have been reported. According to a nationwide survey conducted in Japan from 2008 to 2012, out of 3,815,118 colonoscopy cases, adverse events of bowel preparation were reported in 105 cases $(0.003 \%)$ [14]. Ischemic colitis is recognized as an adverse event of bowel preparation [15-18]. Ischemic colitis occurs when blood flow to the colon is reduced to a level that is insufficient to maintain the metabolic functions of the cells [19]. Most cases of ischemic colitis are transiently cured, but some cases become severe and leave non-reversible sequelae, including strictures and chronic segmental colitis [20]. Ischemic colitis is common in the elderly and has been on the rise in recent years [21]. Various drugs, including laxatives, have been reported to cause ischemic colitis [22]. One large observational study in USA reported a $0.02 \%(62 / 287,323)$ incidence of ischemic colitis due to colonoscopy preparation [23]; however, the risk factors and incidence of preparation-in- 
duced ischemic colitis have not been thoroughly investigated.

The aim of this study was to investigate the incidence of ischemic colitis and the risk factors for ischemic colitis associated with bowel preparations.

\section{Materials and Methods}

\section{Study design}

This was a single-center, retrospective, observational study. All outpatients who were prescribed standardized drugs for colonoscopy preparation at our hospital between November 2011 and March 2020 were included in the study. The incidence and risk factors for ischemic colitis after administration of the preparation drugs were examined. The exclusion criteria were as follows: patients with unclear relationship between the prescription date of the preparation drugs and the colonoscopy date, patients with colonoscopy cancellation, patients with bloody stool as an indication for colonoscopy, patients younger than 40 years old, and patients with stoma.

This study was approved by the Institutional Review Board of the Kyoto Second Red Cross Hospital (Sp2020-14). Informed consent about colonoscopy was obtained from all patients before the procedure.

\section{Bowel preparation}

Two patterns of standardized colonoscopy preparation drugs were used at our facility. In patients without constipation, magnesium citrate $\left(\right.$ Magcorol $^{\circledR}$ P, Horii Pharmaceutical Ind., Ltd., Osaka, Japan) and PEG-ELS (Muben ${ }^{\circledR}$ liquid state, Nihon Pharmaceutical Co., Tokyo, Japan) were administered. Patients were instructed to dissolve Magcorol ${ }^{\circledR} \mathrm{P} 50 \mathrm{~g}$ in water to a total volume of $180 \mathrm{~mL}$ and take it the night before colonoscopy and take 2 L of PEG-ELS in the morning before colonoscopy ("normal" method). For constipated patients, in addition to the above medications, sodium picosulfate hydrate (Laxoberon ${ }^{\circledR}$ solution $0.75 \% 10 \mathrm{~mL}$, Teijin Pharma, Ltd., Tokyo, Japan) was added the night before colonoscopy ("strong" method). In case of difficulty ingesting 2 L of PEG-ELS, 50 sodium phosphate $(\mathrm{NaP})$ tablets (Visiclear ${ }^{\circledR}$ combination tablet, ZERIA Pharmaceutical Co., Ltd., Tokyo, Japan) were used instead of PEGELS only for patients aged below 65 years old who did not have hypertension. No dietary restrictions were indicated on the day before the colonoscopy. In Japan, there are many facilities where nurses check the defecation status after preparation drug administration; and if there are still brown stools, enemas are additionally administered [24]. In our hospital, nurses in the endoscopy center presented the patients with example pictures of stool condition after preparation and asked whether their feces were clear. A saline $(2 \% \mathrm{NaCl})$ enema $(500 \mathrm{~mL})$ was administered if preparation was inadequate.

Gastroenterologists interviewed the patient when prescribing preparation medication. In patients diagnosed with constipation, a "strong" preparation method was recommended. For patients with regular use of laxatives, we also recommended the "strong" method. In cases with concerns about large bowel obstruction, no preparation medication was prescribed, and colonoscopy was performed with enema only.

\section{Study endpoints}

The primary endpoint was the development of ischemic colitis. The secondary endpoints were the quality of preparation evaluated using the Aronchick scale [24] and the proportion of patients who required saline enema because of inadequate preparation.

Usually, ischemic colitis is diagnosed by a combination of onset form, endoscopic findings, biopsy findings, and culture findings [19]. In this study, ischemic colitis was defined as: 1) abdominal pain after taking preparation drugs and endoscopic findings suggestive of early-onset ischemic colitis; and 2) suspicious endoscopic findings of early-onset ischemic colitis and pathologically diagnosed as ischemic colitis by biopsy. The endoscopic findings of ischemic colitis were: segmental edematous and fragile mucosa, scattered erosion, and/or longitudinal ulcerations (Fig. 1) [25].

We categorized disease severity as mild, moderate, or severe according to the guidelines of the American College of Gastroenterology [19]. Patients with mild disease lack the following risk factors for poor prognosis seen in moderate and severe disease: male sex, hypotension (systolic blood pressure $<90 \mathrm{~mm} \mathrm{Hg}$ ), tachycardia (heart rate $>100$ beats $/ \mathrm{min}$ ), abdominal pain without rectal bleeding, blood urea nitrogen $>$ $20 \mathrm{mg} / \mathrm{dL}$, hemoglobin $(\mathrm{Hb})<12 \mathrm{~g} / \mathrm{dL}$, lactate dehydrogenase $(\mathrm{LDH})>350 \mathrm{U} / \mathrm{L}$, serum sodium $<136 \mathrm{mEq} / \mathrm{L}(\mathrm{mmol} / \mathrm{L})$, and white blood cell count $\left.>15 \times 10^{9} / \mathrm{L}\right)$. Moderate disease was defined by up to three of the aforementioned factors. Severe disease was defined by more than three of the previously listed criteria or by any of the following: peritoneal signs, pneumatosis or portal venous gas on radiologic imaging, gangrene on colonoscopy, pancolonic distribution, or isolated right-colon ischemia on imaging or colonoscopy.

\section{Data collection}

All outpatients with a prescription history of colonoscopy preparation drugs were extracted from the electronic medical records and matched with the endoscopy database by examination date and hospital identification number. The database was searched using "ischemia" as a keyword, and cases endoscopically diagnosed with ischemic colitis were reviewed by two gastrointestinal endoscopists (TK and NS); cases judged as ischemic colitis associated with preparation drugs were extracted. The electronic medical record system used was MegaOakHR (NEC Corporation, Tokyo, Japan), and the endoscopic database system used was Solemio QUEV (Olympus Corporation, Tokyo, Japan).

\section{Efforts to address potential sources of bias}

To avoid confusion with patients who had ischemic colitis before taking preparation drugs, we excluded patients with 

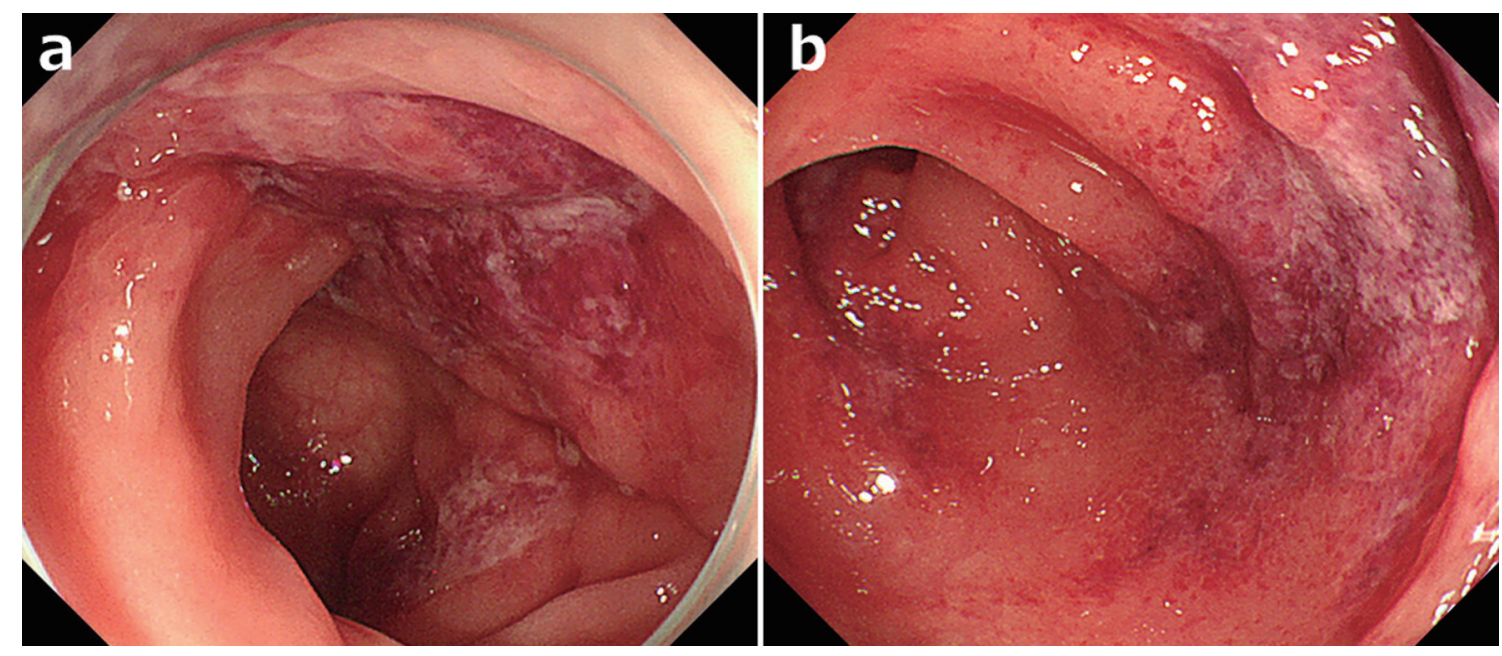

Figure 1. Endoscopic findings of ischemic colitis after taking bowel preparation drugs. (a) Segmental edematous and fragile mucosa. (b) Longitudinal ulcerations.

bloody stool as an indication for colonoscopy. To reduce bias in the parameter estimates led to rare events, we performed logistic regression with Firth's penalized likelihood method described in the next section.

\section{Statistics}

In recent years, the age of 75 years or older has been defined as elderly in Japan [26]; therefore, the age of the patients was categorized into $<75$ years and $\geq 75$ years. The risk of developing ischemic colitis was estimated by multivariate analysis using logistic regression analysis with Firth's penalized likelihood method with age, gender, and type of preparation ("normal" or "strong") as adjustment factors. Regarding secondary endpoints, proportions of poor/inadequate preparation in the Aronchick scale and that of additional saline enema were compared between "normal" and "strong" preparation groups using the Chi-square test. SAS statistical software V.9.4 (SAS Institute) was used for all statistical analyses. The sample size was determined based on the number of cases enrolled in our hospital during the study period.

\section{Results}

During the study period, 20,939 outpatients were prescribed standardized preparation drugs for colonoscopy. Excluding patients who met the exclusion criteria, 14,924 patients were analyzed (Fig. 2). Among the patients analyzed, 21.2\% were aged $\geq 75$ years (Table 1). Regarding the preparation method, $92.0 \%$ of the patients $(13,727 / 14,924)$ were treated with the "normal" method and $8.0 \%(1,197 / 14,924)$ with the "strong" method. The $\mathrm{NaP}$ regimen was used in less than $1 \%$ of cases. The most common indication of colonoscopy was surveillance, followed by a positive fecal occult blood test and screening. The number of patients who underwent therapeutic colonoscopy as an indication for colonoscopy was small because hospitalized patients were not included in this study. Missing data in the item of indication were classified in the category of "unknown." There were no missing data for age, sex, or type of preparation medication.

Overall, ischemic colitis was observed in 14 patients

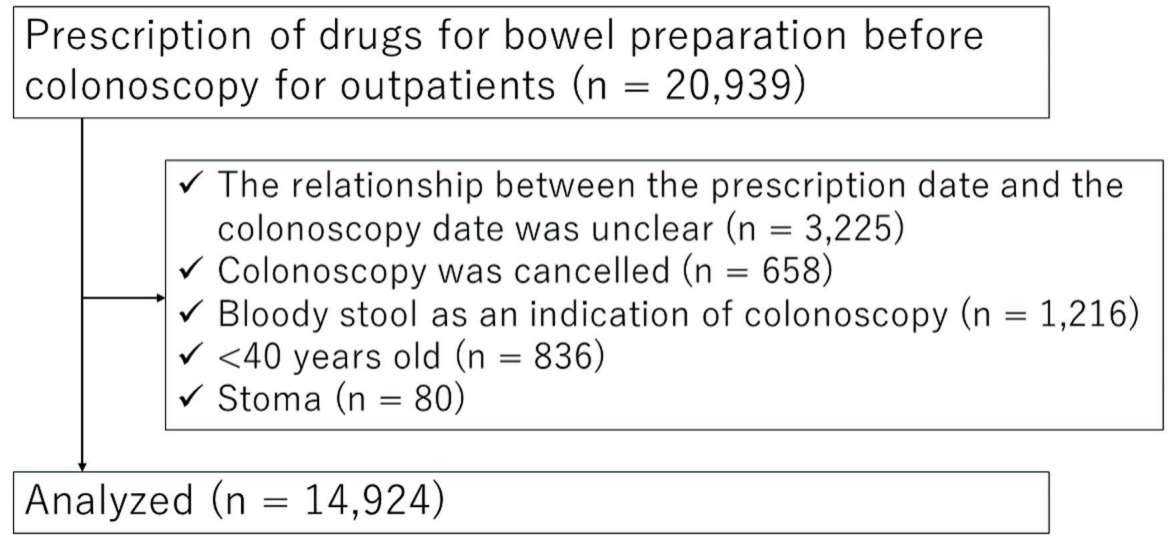

Figure 2. Study flow. 
Table 1. Patient Characteristics

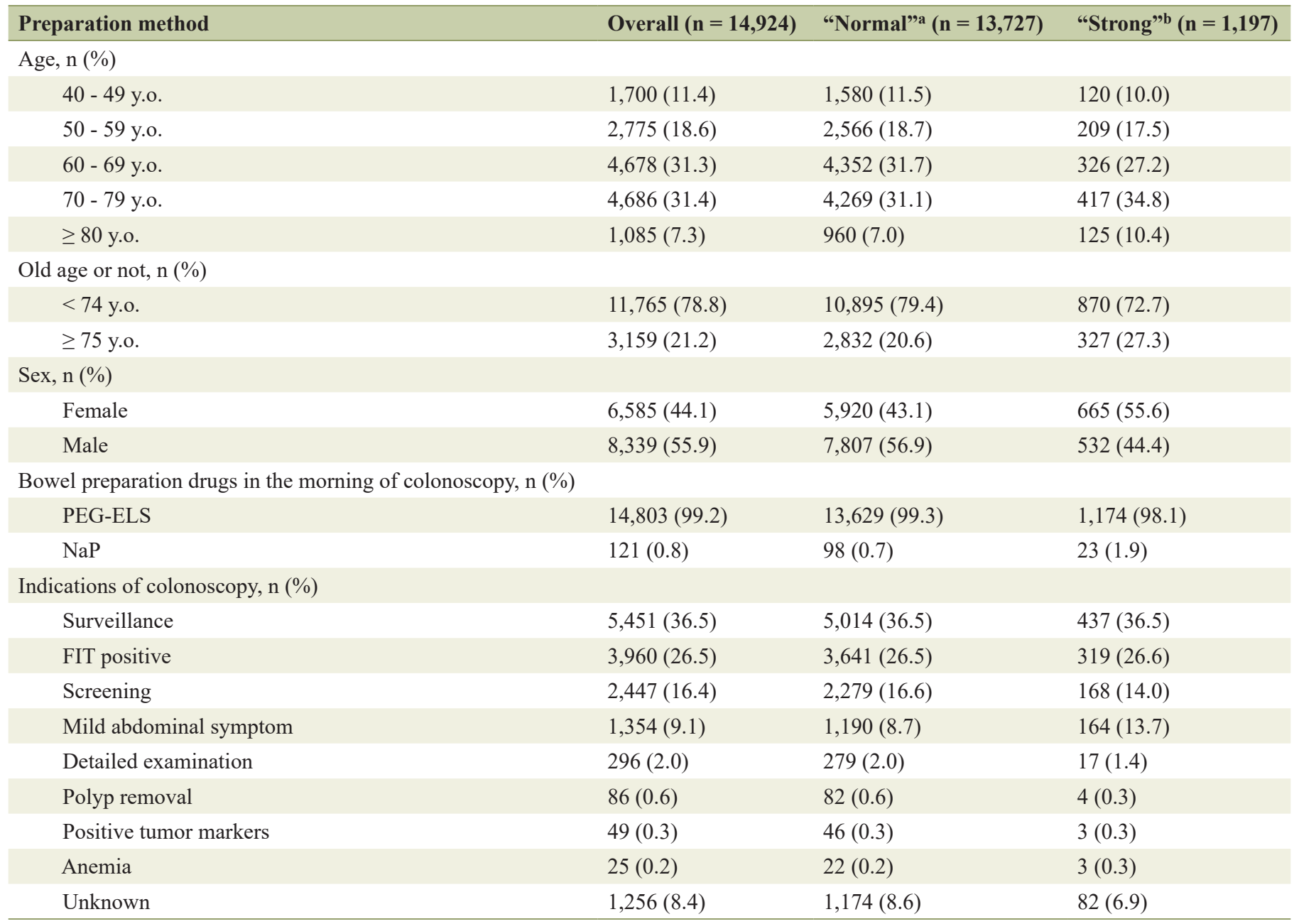

a"Normal": taking magnesium citrate the night before colonoscopy. "Strong": taking sodium picosulfate hydrate in addition to magnesium citrate the night before colonoscopy. y.o.: years old; PEG-ELS: polyethylene glycol electrolyte solution; NaP: sodium phosphate; FIT: fecal immunochemistry test.

$(0.09 \%)$. The incidence of ischemic colitis by age was $0.06 \%$ $(1 / 1,700)$ for patients aged $40-49$ years, $0.04 \%(1 / 2,775)$ for patients aged 50 - 59 years, $0.06 \%(3 / 4,678)$ for patients aged 60 - 69 years, $0.09 \%(4 / 4,686)$ for patients aged 70 - 79 years, and $0.46 \%(5 / 1,085)$ for patients aged 80 years and over. The incidence of ischemic colitis by preparation drugs was $0.07 \%$ (10/13727) for "normal" method and $0.33 \%$ (4/1197) for "strong" method.

According to the results obtained from the multivariate analysis, old age ( $\geq 75$ years old) and "strong" method of preparation were independent risk factors for ischemic colitis due to bowel preparation (odds ratio $=3.64,95 \%$ confidence interval (CI): 1.36 - 9.77; and odds ratio $=4.27,95 \%$ CI: 1.45 - 12.53, respectively; Table 2).

Of the 14 cases of ischemic colitis, details of symptoms before and after the onset of the disease were confirmed by electronic medical records in 11 cases (Table 3). Of these, seven patients had strong abdominal pain, and all of them developed this symptom after taking preparation drugs the night before colonoscopy until the morning of the colonoscopy. It was difficult to strictly classify the severity of the disease because blood tests were not performed at the time of colonoscopy in many cases, but all cases were considered to be mild or moderate. All patients were treated with only observation and supportive care, and their symptoms improved transiently. None of the patients required hospitalization, and there were no cases with sequelae.

As for secondary endpoints, the proportion of poor/inadequate preparation was significantly higher in the "strong" preparation group than in the "normal" group (Table 4; $\mathrm{P}<0.001$ ). The proportion of patients that required additional saline enema was also significantly higher in the "strong" preparation group $(\mathrm{P}<$ $0.001)$.

\section{Discussion}

In this study, the incidence of ischemic colitis due to colonoscopy preparation was $0.09 \%$. Through multivariate analysis, 
Table 2. Risk of Ischemic Colitis Using Multiple Logistic Regression Analysis

\begin{tabular}{lll}
\hline & Odds ratio $(\mathbf{9 5 \%}$ confidence interval) & P value \\
\hline "Normal"a method & 1 (reference) & 0.008 \\
"Strong"b method & $4.27(1.45-12.53)$ & 0.31 \\
Male & 1 (reference) & \\
Female & $1.67(0.62-4.53)$ & 0.01 \\
$<75$ years old & 1 (reference) & \\
$\geq 75$ years old & $3.64(1.36-9.77)$ & \\
\hline
\end{tabular}

a"Normal": taking magnesium citrate the night before colonoscopy. "Strong": taking sodium picosulfate hydrate in addition to magnesium citrate the night before colonoscopy.

Table 3. Ischemic Colitis Cases After Bowel Preparation for Colonoscopy

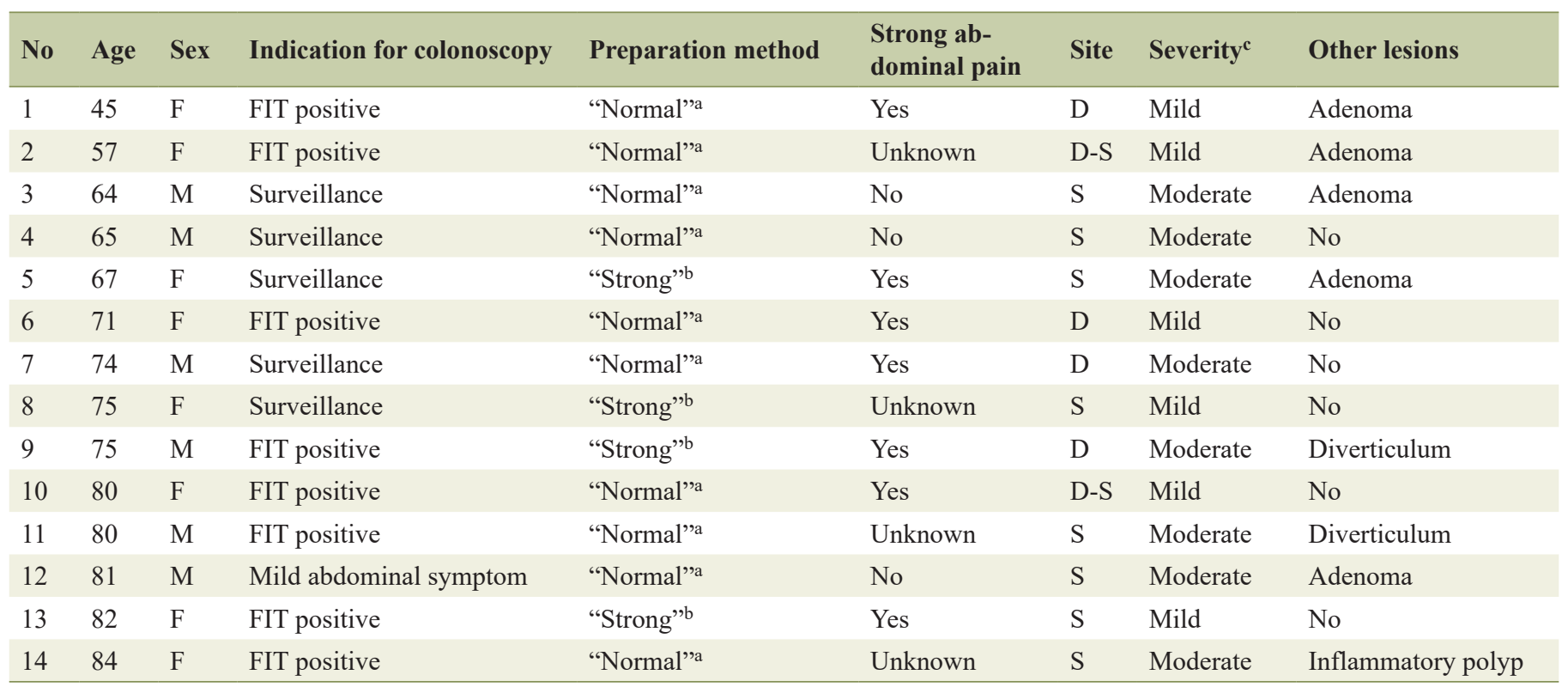

a"Normal": taking magnesium citrate the night before colonoscopy. " "Strong": taking sodium picosulfate hydrate in addition to magnesium citrate the night before colonoscopy. "Severity was determined using only the limited risk factors. M: male; F: female; FIT: fecal immunochemistry test; D: descending colon; S: sigmoid colon.

Table 4. Secondary Endpoints

\begin{tabular}{|c|c|c|}
\hline Preparation method & "Normal"a $(n=13,727)$ & "Strong"b $(n=1,197)$ \\
\hline \multicolumn{3}{|c|}{ Degree of preparation (Aronchick scale), n (\%) } \\
\hline Excellent & $6,672(48.6)$ & $482(40.3)$ \\
\hline Fair & $2,160(15.7)$ & $204(17.0)$ \\
\hline Poor/inadequate & $527(3.8)$ & $81(6.8)$ \\
\hline \multicolumn{3}{|c|}{ Additional saline enema, n (\%) } \\
\hline Yes & $180(1.8)$ & $55(4.6)$ \\
\hline No & $8,749(63.7)$ & $839(70.1)$ \\
\hline Unknown & $4,798(35.0)$ & $303(25.3)$ \\
\hline
\end{tabular}

a"Normal": taking magnesium citrate the night before colonoscopy. "'Strong": taking sodium picosulfate hydrate in addition to magnesium citrate the night before colonoscopy. 
we have demonstrated that the age 75 years and above and "strong" preparation for patients with constipation are independent risk factors for ischemic colitis.

Oral sodium sulfate [16], bisacodyl [17, 18], magnesium citrate $[15,27,28]$ and sodium phosphate [15] are preparation drugs for colonoscopy that have been reported as causes of ischemic colitis. Ischemic colitis caused by colonoscopy preparation is thought to be due to a relative decrease in intestinal blood flow associated with rapid fecal excretion. Although only magnesium citrate, sodium picosulfate hydrate, PEG-ELS, and NaP tablets were the preparation drugs on in this study, ischemic colitis due to rapid fecal excretion may occur even when other preparation drugs are used. Therefore, we believe that the risk factors for ischemic colitis identified in this study can be generalized for other preparation drugs.

The incidence of ischemic colitis in this study was $0.09 \%$, which was higher than that reported in previous studies: < $0.003 \%$ in Japan [14] and $0.02 \%$ in the USA [19]. However, in this study, it was possible to identify milder cases of ischemic colitis due to integration with the endoscopic database, and this may explain the relatively higher incidence of ischemic colitis relative to previous studies.

Since old age is considered a predictor of poor bowel preparation [29, 30], more potent preparation drugs may be necessary for good preparation. In the "strong" preparation method group in this study, the proportions of patients with poor/inadequate preparation and those who required additional enema were higher than those in the "normal" method despite the use of potent preparation drugs. This suggests that even with powerful laxatives, constipated patients were not adequately prepared. However, based on the results of the present study, rapid evacuation of stool in the elderly with constipation by powerful laxatives would be a risk factor for ischemic colitis, and gentle control of bowel movements for several days before colonoscopy may be useful. At our institution, since the preliminary results of this study were released, we have been administering laxatives for 5 days before colonoscopy in patients with constipation, especially the elderly.

In Japan, 12 deaths due to preparation prior to colonoscopy were reported between October 2015 and April 2019 [31]. In our current study, there were only mild and moderate cases but no severe cases. Ischemic colitis can be fatal in severe cases [19]. To prevent death due to colonoscopy preparation, great care is needed for elderly and constipated patients.

The present study had several limitations. First, this was a single-center, retrospective study, and the clinical course of several cases was not properly documented in the medical records. In addition, there was a selection bias in which the "strong" method was chosen only in cases of constipation; thus, we could not distinguish whether constipation or the "strong" method was the risk factor for ischemic colitis. Second, only ischemic colitis confirmed by an endoscopic report was used as an outcome in this study. If the patient had severe ischemic colitis, a colonoscopy might not have been performed. In addition, mild ischemic changes might not have been properly documented in the report. Therefore, the present study may have underestimated the incidence of ischemic colitis. Third, the low frequency of ischemic colitis made it difficult to adjust for a large number of background factors in the multivariate analysis.
Despite the above limitations, the present study provides important information regarding the safety of colonoscopy preparation. The age 75 years and above and "strong" preparation for patients with constipation were independent risk factors for ischemic colitis prior to colonoscopy. The prescription of bowel preparation drugs for patients aged $\geq 75$ years and for those with constipation should be performed with caution. Further multicenter investigation is needed to evaluate these results.

\section{Acknowledgments}

We would like to thank Editage for English language editing. We also thank the staff of the endoscopy center at Kyoto Second Red Cross Hospital for their contributions to this study.

\section{Financial Disclosure}

None to declare.

\section{Conflict of Interest}

This study was self-funded. Author IY reports grants from KAKENHI, AMED, and Health, Labor and Welfare Policy Research Grants, research fund by Nihon Medi-Physics, and speaker fees from Chugai Pharmaceutical Co, AstraZeneca plt, Japan Tabacco Pharamaceutical Division, and Nippon Shinyaku Co, outside the submitted work. The other authors declare no conflict of interest.

\section{Informed Consent}

Informed consents were obtained.

\section{Author Contributions}

TK: study concept and design, acquisition of data, analysis and interpretation of data, and drafting of the manuscript. NS: acquisition and interpretation of data. KT: acquisition of data and technical support. IY: statistical review. KU and KY: study supervision. All the authors approved the final version of the manuscript.

\section{Data Availability}

Any inquiries regarding supporting data availability of this study should be directed to the corresponding author.

\section{References}

1. Projected Cancer Statistics, 2018. Natoinal Cancer Cent- 
er. https://ganjoho.jp/en/public/statistics/short pred.html. Accessed April 12, 2020.

2. Loberg M, Kalager M, Holme O, Hoff G, Adami HO, Bretthauer M. Long-term colorectal-cancer mortality after adenoma removal. N Engl J Med. 2014;371(9):799807.

3. Nishihara $\mathrm{R}, \mathrm{Wu} \mathrm{K}$, Lochhead P, Morikawa T, Liao $\mathrm{X}$, Qian ZR, Inamura $\mathrm{K}$, et al. Long-term colorectalcancer incidence and mortality after lower endoscopy. N Engl J Med. 2013;369(12):1095-1105.

4. Zauber AG, Winawer SJ, O'Brien MJ, Lansdorp-Vogelaar I, van Ballegooijen M, Hankey BF, Shi W, et al. Colonoscopic polypectomy and long-term prevention of colorectal-cancer deaths. N Engl J Med. 2012;366(8):687-696.

5. Brenner H, Chang-Claude J, Seiler CM, Rickert A, Hoffmeister M. Protection from colorectal cancer after colonoscopy: a population-based, case-control study. Ann Intern Med. 2011;154(1):22-30.

6. Baxter NN, Goldwasser MA, Paszat LF, Saskin R, Urbach DR, Rabeneck L. Association of colonoscopy and death from colorectal cancer. Ann Intern Med. 2009;150(1):1-8.

7. Corley DA, Jensen CD, Marks AR, Zhao WK, Lee JK, Doubeni CA, Zauber AG, et al. Adenoma detection rate and risk of colorectal cancer and death. N Engl J Med. 2014;370(14):1298-1306.

8. Kaminski MF, Regula J, Kraszewska E, Polkowski M, Wojciechowska U, Didkowska J, Zwierko M, et al. Quality indicators for colonoscopy and the risk of interval cancer. N Engl J Med. 2010;362(19):1795-1803.

9. Asge Standards of Practice Committee, Saltzman JR, Cash BD, Pasha SF, Early DS, Muthusamy VR, Khashab $\mathrm{MA}$, et al. Bowel preparation before colonoscopy. Gastrointest Endosc. 2015;81(4):781-794.

10. Sano Y, Chiu HM, Li XB, Khomvilai S, Pisespongsa P, Co JT, Kawamura T, et al. Standards of diagnostic colonoscopy for early-stage neoplasia: Recommendations by an Asian private group. Dig Endosc. 2019;31(3):227-244.

11. Clark BT, Rustagi T, Laine L. What level of bowel prep quality requires early repeat colonoscopy: systematic review and meta-analysis of the impact of preparation quality on adenoma detection rate. Am J Gastroenterol. 2014;109(11):1714-1723.

12. Johnson DA, Barkun AN, Cohen LB, Dominitz JA, Kaltenbach T, Martel M, Robertson DJ, et al. Optimizing adequacy of bowel cleansing for colonoscopy: recommendations from the US multi-society task force on colorectal cancer. Gastroenterology. 2014;147(4):903-924.

13. Sharma VK, Chockalingham SK, Ugheoke EA, Kapur A, Ling PH, Vasudeva R, Howden CW. Prospective, randomized, controlled comparison of the use of polyethylene glycol electrolyte lavage solution in four-liter versus twoliter volumes and pretreatment with either magnesium citrate or bisacodyl for colonoscopy preparation. Gastrointest Endosc. 1998;47(2):167-171.

14. Furuta T, Kato M, Ito T, Inaba T, Omura N, Katanuma A, et al. Shokaki Naishikyo Kanren no Guuhatsusyo ni Kansuru Dai 6-kai Zenkokutyosa Houkoku 2008-2012 nen Madeno 5-nenkan (Sixth national survey report on gastrointestinal endoscopy-related complications - 5 years from
2008 to 2012). Gastroenterol Endosc. 2016;58(9):14661491 (in Japanese).

15. Oh JK, Meiselman M, Lataif LE, Jr. Ischemic colitis caused by oral hyperosmotic saline laxatives. Gastrointest Endosc. 1997;45(3):319-322.

16. Chung JW, Lee JM, Sohn YW, Han WC, Yoon K. Ischemic Colitis Associated with Low-volume Oral Sulfate Solution for Bowel Preparation. Korean J Gastroenterol. 2020;75(4):216-219.

17. Baudet JS, Castro V, Redondo I. Recurrent ischemic colitis induced by colonoscopy bowel lavage. Am J Gastroenterol. 2010;105(3):700-701.

18. Lopez Morra HA, Fine SN, Dickstein G. Colonic ischemia with laxative use in young adults. Am J Gastroenterol. 2005;100(9):2134-2136.

19. Brandt LJ, Feuerstadt P, Longstreth GF, Boley SJ, American College of G. ACG clinical guideline: epidemiology, risk factors, patterns of presentation, diagnosis, and management of colon ischemia (CI). Am J Gastroenterol. 2015;110(1):18-44; quiz 45.

20. Greenwald DA, Brandt LJ. Colonic ischemia. J Clin Gastroenterol. 1998;27(2):122-128.

21. Yadav S, Dave M, Edakkanambeth Varayil J, Harmsen WS, Tremaine WJ, Zinsmeister AR, Sweetser SR, et al. A population-based study of incidence, risk factors, clinical spectrum, and outcomes of ischemic colitis. Clin Gastroenterol Hepatol. 2015;13(4):731-738 e731-736; quiz e741.

22. Hass DJ, Kozuch P, Brandt LJ. Pharmacologically mediated colon ischemia. Am J Gastroenterol. 2007;102(8):1765-1780.

23. Anastassopoulos K, Farraye FA, Knight T, Colman S, Cleveland MV, Pelham RW. A comparative study of treatment-emergent adverse events following use of common bowel preparations among a colonoscopy screening population: results from a post-marketing observational study. Dig Dis Sci. 2016;61(10):2993-3006.

24. Saito Y, Oka S, Kawamura T, Shimoda R, Sekiguchi M, Tamai N, Hotta K, et al. Colonoscopy screening and surveillance guidelines. Dig Endosc. 2021;33(4):486-519.

25. Zou X, Cao J, Yao Y, Liu W, Chen L. Endoscopic findings and clinicopathologic characteristics of ischemic colitis: a report of 85 cases. Dig Dis Sci. 2009;54(9):2009-2015.

26. Ouchi Y, Rakugi H, Arai H, Akishita M, Ito H, Toba K, Kai I, et al. Redefining the elderly as aged 75 years and older: Proposal from the Joint Committee of Japan Gerontological Society and the Japan Geriatrics Society. Geriatr Gerontol Int. 2017;17(7):1045-1047.

27. Sugiyama M, Kusumoto E, Ota M, Kimura Y, Tsutsumi N, Oki E, Sakaguchi Y, et al. Induction of potentially lethal hypermagnesemia, ischemic colitis, and toxic megacolon by a preoperative mechanical bowel preparation: report of a case. Surg Case Rep. 2016;2(1):18.

28. Kontani M, Hara A, Ohta S, Ikeda T. Hypermagnesemia induced by massive cathartic ingestion in an elderly woman without pre-existing renal dysfunction. Intern Med. 2005;44(5):448-452.

29. Lukens FJ, Loeb DS, Machicao VI, Achem SR, Picco MF. Colonoscopy in octogenarians: a prospective outpa- 
tient study. Am J Gastroenterol. 2002;97(7):1722-1725.

30. Jafri SM, Monkemuller K, Lukens FJ. Endoscopy in the elderly: a review of the efficacy and safety of colonoscopy, esophagogastroduodenoscopy, and endoscopic retrograde cholangiopancreatography. J Clin Gastroenterol. 2010;44(3):161-166.
31. Japan Medical Safey Medical Reserch Organization. Daityonaishikyo Kensanado-no Zensyoti-ni-kakaru Shibojirei-no Bunseki (Analysis of deaths related to bowel preparation before colonoscopy). https://www.medsafe. or.jp/uploads/uploads/files/teigen-10.pdf. Accessed July 24, 2020 (in Japanese). 